\title{
The effect of jury size and judge's instructions on memory for pragmatic implications from courtroom testimony
}

\author{
RICHARD J. HARRIS \\ Kansas State University, Manhattan, Kansas 66506
}

\begin{abstract}
Subjects working in groups of one, two, and three heard an excerpt of courtroom testimony and were later asked to rate statements about material in the testimony as true, false, or of indeterminate truth value. Half of the subjects heard any given piece of information (Mr. X rang the burglar alarm) directly asserted (I rang the burglar alarm), while the other half heard it only implied ( $I$ ran up to the burglar alarm). Half of the subjects initially heard specific instructions about the pitfalls of interpreting implied information as if it were asserted fact, while the other half heard no such instructions. Subjects in both groups remembered a majority of implications as true. The implication instructions did not significantly reduce the number of implied statements remembered as true, and there were no differences as a function of group size.
\end{abstract}

Although many errors in memory for verbal material involve only a change in wording or syntax, there are also memory distortions that alter the meaning of an utterance. One class of such distortions to occur widely in sentence memory is remembering what was pragmatically implied instead of what was directly stated. Harris and Monaco (in press) discuss pragmatic implication, which exists when an utterance leads the hearer to expect something neither explicitly stated nor necessarily implied. For example, The karate champion hit the cement block pragmatically implies that he broke the block, when in fact he may have only hit it without breaking it, and The hungry python caught the mouse pragmatically implies that the snake ate the mouse, although the mouse may have escaped before becoming the snake's dinner.

A number of recent studies have found that subjects often remember not what is directly stated in a sentence but rather what is pragmatically implied by it. This result has been found with cued recall (Brewer, in press; Brewer \& Lichtenstein, 1975), recognition memory (Johnson, Bransford, \& Solomon, 1973), and true-false judgments of related sentences (Harris, 1974). It has also been obtained using advertisements (Harris, 1977), courtroom testimony (Harris, Teske, \& Ginns, 1975), and leading questions (Loftus \& Palmer, 1974; Loftus \& Zanni, 1975) as stimulus materials.

This work was supported by a grant from the Kansas State University Faculty Research Award Committee. Results were presented at the Psychonomic Society Meeting, St. Louis, November 1976. Appreciation is expressed to Patricia Martin for data collection and analysis and Ross Teske for writing the implication instructions. Requests for reprints should be sent to Richard J. Harris, Department of Psychology, Anderson Hall, Kansas State University, Manhattan, Kansas 66506.
Although making inferences from such implications may usually be helpful in language comprehension, there are times when it is misleading. Memory for courtroom testimony by a jury during deliberation is a situation where the distinction between direct assertions and pragmatic implications is potentially critical. If the memory distortion that occurred in the laboratory also occurs in the courtroom setting, it could have serious consequences for the implementation of justice through the jury trial, where the jury is to evaluate the facts, not what the facts suggest. Harris et al. (1975) had subjects listen to an excerpt from a burglary trial and either immediately or 2 days later judge related sentences as true, false, or of indeterminate truth value, based on the trial excerpt. They found that there was no difference between the number of true responses to sentences whose truth was implied by the testimony and those whose truth was directly asserted and no difference as a function of input-task delay.

The devious use of pragmatic implication in the courtroom has long been practiced by both lawyers and witnesses; a witness must swear to tell only the truth but not necessarily to imply only the truth. $\mathrm{He} / \mathrm{she}$ is liable for perjury for false assertions but not for false implications, even if these implications may be remembered by the jury as facts. All character witnesses are introduced not for what their testimony asserts but rather for what it implies about the defendant's guilt or innocence. Lawyers may attempt to introduce blatantly improper evidence or ask clearly leading questions, with the full knowledge that they will be immediately ruled out of order, but not before the jury has heard the information and processed the pragmatic implications. A simple statement from the judge to jury to disregard certain evidence may not be enough to stop one's information processing system from compre- 
hending the biased data and entering it into memory (Sue, Smith, \& Caldwell, 1973).

The present study was an extension of the Harris et al. (1975) study in the further study of the memory for pragmatic implications in courtroom testimony. An instructions variable was examined to determine if the jurors' memory of implications as assertions could be reduced by specific instructions to them, carefully distinguishing asserted from implied information. In any trial, the judge gives a variety of explanations ("pattern instructions") to the jury to clarify legal terms, evaluation of evidence, and so on. If instructions to discriminate assertions and implications were to reduce what seems to be a general cognitive trend (Harris \& Monaco, in press), it would be relatively easy to introduce such a corrective measure to actual courtroom procedure. In a study of the interpretation of implied product claims in advertising, Harris (1977) found that such instructions were helpful under certain conditions.

A second variable examined in the present study was jury size. The subjects performed the response task either singly or in collaborative groups of two or three. The prediction was that subject-jurors deliberating in groups, as do real juries, would be more likely to discriminate in memory between asserted and implied information, especially in the implication-instructions group, since, if any one member of the group remembered the inferred nature of the statement, he/she could attempt to convince the other members. Thus the present study more closely approximated a real-world jury deliberation situation than did the Harris et al. (1975) study.

\section{METHOD}

\section{Subjects}

The subjects were 72 undergraduate psychology students at Kansas State University; they received extra course credit for participation and were run in 12 groups of one person each, 12 groups of two, and 12 groups of three.

\section{Materials}

A 5-min segment of simulated trial testimony was the stimulus material. At the beginning of the testimony, the witness, a male investment broker at a securities firm, is sworn in; the rest of the tape consists of one attorney's questions and the witness's answers. The testimony concerns the witness's discovery of an apparent burglary; which he comes upon one evening on returning to work after dinner. The questions concern such events as the appearance of the office, actions of the witness, and the arrival of the police. In the testimony of the witness are 18 critical sentences, each of which can occur in two alternate forms, one a direct assertion of some piece of information and the other a pragmatic implication of that information. The pragmatic implications were of the sort discussed by Harris and Monaco (in press). Sample statements of the witness, in their assertion and implication forms, appear in Table 1. Two tapes of the testimony were recorded, with every critical sentence that appeared as an assertion in Tape 1 occurring as an implication in Tape 2 and vice versa. There were nine assertions and nine implications on each tape.

\section{Design and Procedure}

The experiment was a 2 by 2 by 3 design with a withinsubjects variable of item type (assertion or implication) and two between-subjects variables of instructions type (no instructions or implication instructions) and jury size (one, two, or three persons). Half of the subjects in each instructions by jury size group heard Tape 1 and half heard Tape 2.

All subjects were told that they were participating in a study of how people evaluate evidence presented in a jury trial. They were told to pretend that they were on the jury and listen to the trial excerpt, after which they would be asked some questions about what they had heard. The no-instructions subjects then heard either Tape 1 or 2 , while the instructions subjects first heard the following additional instructions, read by the experimenter: "There are many ways to influence your memory on what is said and what happens in the courtoom. An implicating statement, question, or presentation is extremely effective in influencing your opinions and memory.

"An example of an implicating statement is 'The hungry python caught the mouse.' This suggests that the snake ate the mouse and the statement will probably be remembered that way; that is, that he ate the mouse. The statement did not say the snake ate the mouse; it only highly suggested that he did. In court it is more likely that you will hear a statement like 'The speeding car hit the pedestrian.' This suggests that the car hurt the pedestrian, while in fact the car may have had its brakes applied and only tapped the pedestrian. Many times the implication is more subtle. For example, consider the difference between 'The mother's child was killed' and 'The patient's fetus was killed,' the first implying that the unborn was a legal person but the second implying that the unborn was not a person.

"An example of an implicating question is 'Do you still beat your wife?' This suggests the recipient of the question has beaten his wife before, even if he answers 'no' to the question. Even a minor change in a sentence or question can make a big difference. For example, the question 'Did you see the broken headlight?' suggests there was a broken headlight and asks if you saw it, when it would have been more proper to ask 'Did you see a broken headlight?' meaning there might have been a broken headlight and asking if by chance you saw such an object.

Table 1

Sample Critical Statements by Witness and Test Items

\begin{tabular}{lll}
\hline \multicolumn{1}{c}{ Assertion } & \multicolumn{1}{c}{ Implication } & Test Item \\
\hline $\begin{array}{l}\text { 1. I rang the burglar alarm in the hall. } \\
\text { 2. I walked away without taking any } \\
\text { money. }\end{array}$ & $\begin{array}{l}\text { I was able to walk away without taking } \\
\text { any money. }\end{array}$ & $\begin{array}{l}\text { Mr. Ranson walked away from the office } \\
\text { safe without taking any money, after he } \\
\text { found the safe open. }\end{array}$ \\
$\begin{array}{l}\text { 3. That absent-minded Herman lost his } \\
\text { walkie-talkie. }\end{array}$ & $\begin{array}{l}\text { That absent-minded Herman didn't have } \\
\text { his walkie-talkie either. }\end{array}$ & $\begin{array}{l}\text { Herman Lyons, the night watchman, had } \\
\text { lost his walkie-talkie. }\end{array}$
\end{tabular}


"You can be influenced by a leading question or any implicating presentation even if it is sustained or considered invalid. A question or presentation can influence your comprehension and memory by the implications it implies. The implication may influence you to believe what the attorney or witness wants you to believe. You must be alert so that you will not be affected by implications but only affected by facts."

These instructions were written especially for this research but were embedded within a series of actual pattern instructions, unrelated to the issue of implication, which were regularly used in the District Court of Riley County, Kansas. Such instructions thus helped the experiment to more closely approximate a real courtroom situation and insure that the critical implication instructions were embedded in other material equally appropriate for the occasion of a trial.

Immediately after the tape was finished, the subjects were given an answer sheet containing 36 statements which they were to judge (based on the taped testimony) as true, false, or indeterminate (tape did not make clear if true or false). The groups of two and three were given a single answer sheet and asked to discuss and come to an agreement on one answer for the group to each question. The 18 even-numbered items were statements that were either asserted or implied by the testimony (see Table 1 for examples). These statements occurred in the order in which that information had occurred in the testimony. The 18 odd-numbered items were fillers and consisted of nine statements that were clearly false, based on the testimony, and nine that were not mentioned in the testimony and thus should be checked indeterminate in truth value. The false and indeterminate control items were included to prevent an otherwise strong response bias toward true responses. The subjects worked through the task at their own speed.

\section{RESULTS}

Table 2 summarizes the mean numbers of true responses to assertion and implication items by groups of subjects in the instructions by jury size conditions. Two 2 by 2 by 3 analyses of variance, treating both subject groups and items as random factors (Clark, 1973), were performed on the number of true responses on the 18 critical sentences. There were significantly more trues for assertions than implications $\left[\mathrm{F}_{1}(1,30)=\right.$ $\left.47.69, \mathrm{~F}_{2}(1,17)=11.01, \min \mathrm{F}^{\prime}(1,25)=8.95, \mathrm{p}<.01\right]$. However, neither instructions nor group size had a sig. nificant effect, nor was any interaction significant. There were, however, somewhat fewer trues in the implicationinstructions group than the no-instructions group, though the difference was not significant under the conservative $\min \mathrm{F}^{\prime}$ estimate $\left[\mathrm{F}_{1}(1,30)=3.05\right.$, $\left.F_{2}(1,17)=6.28, \min F^{\prime}(1,47)=2.06, p>.10\right]$.

\section{DISCUSSION}

The results produced the distressing finding that even very explicit instructions not to interpret implied information as fact did not significantly reduce the number of responses doing just that, although there was a nonsignificant trend in that direction. In a recent study of the effect of instructions in attenuating the hindsight bias in estimating probabilities of uncertain events, Fischhoff (1977) has obtained similar results, in that very obtrusive instructions did little to alter the inappropriate manner of processing the information.

The question of whether it is possible to "instruct out" the fallacy of remembering implications as asserted information remains. In the courtroom setting, if such effective instructions could be developed, they could readily be inserted into a judge's
Table 2

Mean Number of "True" Responses (Out of Nine) on Assertion (A) and Implication (I) Items

\begin{tabular}{|c|c|c|c|c|c|}
\hline \multirow[b]{3}{*}{ Jury Size } & \multicolumn{4}{|c|}{ Condition } & \multirow[b]{3}{*}{ Mean } \\
\hline & \multicolumn{2}{|c|}{ No Instructions } & \multicolumn{2}{|c|}{ Instructions } & \\
\hline & A & I & A & I & \\
\hline One Person & 7.83 & 6.17 & 6.67 & 5.17 & 6.46 \\
\hline Two Person & 8.17 & 6.33 & 7.17 & 5.50 & 6.79 \\
\hline Three Person & 7.67 & 5.67 & 7.83 & 5.67 & 6.71 \\
\hline Mean & 7.89 & 6.06 & 7.22 & 5.44 & 6.65 \\
\hline
\end{tabular}

instructions to the jury, either before or after the presentation of evidence. In a study using the same procedure but advertisements instead of testimony, Harris (1977) found that instructions such as those used in the present study were effective in reducing the number of "trues" to implication items, but only if the test sentences were evaluated immediately after hearing their corresponding advertisements. Bruno (1977) obtained an effect of instructions in long-term memory, but the instructions in her study took the form of a 15-min training session, where subjects performed written exercises discriminating assertions and implications and also discussed the distinction with the experimenter. Thus it appears that it may be possible to successfully teach subjects to discriminate assertions and implications, but the training must be more obtrusive and intensive than merely having subjects listen to an explanation embedded in a context of irrelevant material.

Although there were significantly fewer trues to implications than to assertions, there were still a disturbing number of responses of "true" to the implication items (64\% overall), with the smallest cell mean in Table 2 showing more than $57 \%$ of the implication items answered "true." In well over half of the implication items, subjects remembered the information as directly asserted, a finding also obtained using advertisements as experimental materials (Harris, 1977). This seems to be a general information processing phenomenon and should be a matter of considerable concern to psychologists and legal scholars, as well as the general public.

The failure to obtain a main effect, or even a sizable ordinal trend, of jury size further attests to the strength of the tendency to interpret and remember implied information as asserted. One might reasonably predict that there would be fewer true responses to implication items in the larger groups of subjects, where, presumably, if any one subject "caught" the implication, he/she could so inform the others and so sway the group decision. There was absolutely no evidence for such a conclusion, however, nor was there any interaction to suggest that such happened only in the group receiving implication instructions. This finding is consistent with the conclusions of Monaco (1976), who argues that implied information is stored as fact and not merely retrieved as such. Of course, a real jury is considerably larger than the group size examined in the present study, but these results certainly do not suggest the possibility of any attenuation of the effect with the addition of more people to the jury.

In terms of a real courtroom situation, in contrast to the recorded trial excerpt in the present study, one can only speculate that, with longer time intervals and far more additional information to interfere, that the confusion of pragmatic implication and asserted fact is widespread. Attorneys and judges should be alerted to the assertion-implication distinction and insist on a witness's clarification when he/she utters potentially critical testimony in the form of a pragmatic implication. If the witness is not willing to directly assert the information in question, and thus become liable for perjury if he/she is willfully prevaricating, this disposition should be made abundantly clear to the jury. If the uttered implication is understood by the witness to be fact, then it should be so unambiguously stated. 


\section{REFERENCES}

Brewer, W. F. Memory for the pragmatic implications of sentences. Memory \& Cognition, in press.

BREWER, W. F.. \& LiChTENSTEIN, E. H. Recall of logical and pragmatic implications in sentences with dichotomous and continuous antonyms. Memory \& Cognition, 1975, 3, 315-318.

BRUNo, K. J. Training the distinction of pragmatic implications from direct assertions in adolescents and adults. Master's thesis, Kansas State University, 1977.

C LARK. H. H. The language-as-fixed-effect fallacy: A critique of language statistics in psychological research. Journal of Verbal Learning and Verbal Behavior, 1973, 12. 335-359.

Fischноғ, B. Perceived informativeness of facts. Journal of Experimental Psychology: Human Perception and Performance, 1977, 3, 349-358.

HARRIS, R. J. Memory and comprehension of implications and inferences of complex sentences. Journal of Verbal Learning and Verbal Behavior, 1974, 13, 626-637.

HARRIs, R. J. Comprehension of pragmatic implications in advertising. Journal of Applied Psychology, 1977. 62 , 603-608.
HaRRIs, R. J., \& Monaco, G. E. The psychology of pragmatic implication: Information processing between the lines. Journal of Experimental Psychology: General, in press.

HaRRIS, R. J., TESKe, R. R., \& Ginns, M. J. Memory for pragmatic implications from courtroom testimony. Bulletin of the Psychonomic Society, 1975, 6, 494-496.

Johnson, M. K., Bransford, J. D., \& Solomon, S. K. Memory for tacit implications of sentences. Journal of Experimental Psychology, 1973, 98, 203-205.

Loftus, E. F., \& Palmer, J. C. Reconstruction of automobile destruction: An example of the interaction between language and memory. Journal of Verbal Learning and Verbal Behavior, 1974, 13, 585-589.

Loftus, E. F.. \& ZanNI, G. Eyewitness testimony: The influence of the wording of a question. Bulletin of the Psychonomic Society, 1975, 5, 86-88.

Monaco, G. E. Construction as a storage phenomenon. Master's thesis, Kansas State University, 1976.

Sue, S., Smith, R. E., \& Caldwell, C. Effects of inadmissible evidence on the decisions of simulated jurors: A moral dilemma. Journal of Applied Social Psychology, 1973, 3. 345-353.

(Received for publication October 14, 1977.) 